Muhamad Abdul Jumali dan Yitno Utomo: Perencanaan Kebutuhan Kapasitas Waktu Produksi Produk Spon Alas Tidur (Studi Kasus: Perusahaan Alas Tempat Tidur di Sidoarjo)

\title{
PERENCANAAN KEBUTUHAN KAPASITAS WAKTU PRODUKSI PRODUK SPON ALAS TIDUR (Studi Kasus: Perusahaan Alas Tempat Tidur Di Sidoarjo)
}

\author{
1) Muhamad Abdul Jumali, ${ }^{1)}$ Yitno Utomo \\ 1) Program Studi Teknik Industri, Fakultas Teknologi Industri \\ Universitas PGRI Adi Buana Surabaya \\ Email : abduljumali@unipasby.ac.id
}

\begin{abstract}
Abstrak
Pemenuhan kebutuhan konsumen terhadap produk akan mempengaruhi perusahaan secara langsung, maka diperlukan perhitungan pengendalian produksi lebih tepat dan cermat. Permasalahan global perusahaan penghasil spon alas tidur saat ini adalah adanya selisih perhitungan antara kebutuhan kapasitas waktu produksi dengan kapasitas sumber daya yang dimiliki. Sehingga dibutuhkan perencanaan antara kapasitas sumber daya dengan kapasitas kebutuhan waktu produksi guna meningkatkan kinerja perusahaan dalam aktifitasnya. Maka metode yang digunakan dalam artikel ini adalah metode Rough Cut CapacityPlanning $(R C C P)$. Hasil studi kasus ini dapat disimpulkan bahwa Coiller work center dan Bend Frame work center mengalami over capacity.
\end{abstract}

Kata Kunci: Perencanaan Kapasitas, Waktu Produksi, Rough Cut Capacity Planning

\begin{abstract}
Fulfillment of consumer needs for the product will affect the company directly, it is necessary to calculate production controls more precisely and carefully. The global problem of today's sponge bedding producing companies is the difference in calculation between the need for production time capacity and the capacity of the resources they have. So that it takes planning between resource capacity and the capacity of production time needs to improve company performance in its activities. Then the method used in this article is the Rough Cut Capacity Planning (RCCP) method. The results of this case study can be concluded that Coiller work center and Bend Frame work centers experience over capacity.
\end{abstract}

Keywords: Capacity Planning, Production Time, Rough Cut Capacity Planning 
Muhamad Abdul Jumali dan Yitno Utomo: Perencanaan Kebutuhan Kapasitas Waktu Produksi Produk Spon Alas Tidur (Studi Kasus: Perusahaan Alas Tempat Tidur di Sidoarjo)

\section{PENDAHULUAN}

Dalam era revolusi industri 4.0 saat ini, dihadapkan pada tingkat persaingan kompetitif antar perusahaan. Guna meningkatkan kinerja dan laba, diperlukan perencanaan konsep yang tepat dan cermat dalam memenangkan persaingan. Sehingga diperlukan upaya optimalisasi biaya produksi dengan memperhatikan perencanaan kapasitas kebutuhan waktu produksi dengan kapasitas sumber daya yang dimiliki perusahaan. Hal ini dapat memberikan dampak secara langsung terhadap kinerja dan tingkat keuntungan perusahaan, ini terbukti dari banyaknya finishing goods menumpuk di gudang atau pasar mengalami keterlambatan dalam pendistribusian sehingga mengakibatkan hilangnya loyalitas pelanggan terhadap produk. Dalam pengendalian produksi, perusahaan telah mengalami peningkatan biaya penyimpanan dan penambahan biaya jam kerja lembur serta penambahan biaya bahan baku. Sehingga keuntungan yang diharapkan akan jauh dari harapan dan kinerja secara umum perusahaan dianggap menurun atau cenderung mengalami kegaalan dalam produksi. Pengendalian produksi meliputi merencanakan produksi termasuk didalamnya adalah perkiraan permintaan pasar (forecasting), perencanaan pengadaan bahan baku (raw material planning), master production schedule penyelesaian finishing goods.

Dalam studi kasus ini di ungkap sebuah masalah yaitu keseimbangan antara kapasitas kebutuhan waktu produksi dengan ketersediaan kapasitas sumber daya/ resource di lantai produksi. Sebuah hasil penelitian Rumiris (2015) diungkapkan bahwa pada perusahaan yang memproduksi peralatan rumah tangga, dengan melakukan perencanaan kapasitas yakni dengan melakukan penyesuaian beban kerja dan penambahan jam lembur pada beberapa work center yang mengalami kekurangan kapasitas, dapat memberikan kenaikan pendapatan pada perusahaan sebesar $\mathrm{Rp}$. 808.917.600 atau sebesar 31,06\%. Dengan pendekatan Rough Cut Capaciy Planning diharapkan dapat memberikan kontribusi nyata pemegang keputusan tentang perencanaan kapasitas kebutuhan waktu produksi, sehingga waktu proses pembuatan produk spon alas tempat tidur mencukupi dan sesuai master production schedule.

\section{METODE}

Studi kasus ini dilaksanakan di Perusahan spon alas tempat tidur di Sidoarjo selama 3 bulan di tahun 2018. Populasi dalam studi kasus ini adalah spon alas tempat tidur level kualitas paling rendah atau low end grade. Pengambilan sampel dalam studi kasus ini menggunakan teknik sampel jenuh, artinya seluruh jumlah populasi menjadi bagian dari sampel studi kasus ini. Definisi operasional variabel dalam studi kasus ini dijelaskan dalam tabel 1 sebagai berikut:

Tabel 1. Operasional Variabel dan indicator

\begin{tabular}{cll}
\hline No & \multicolumn{1}{c}{ Variabel } & \multicolumn{1}{c}{ Indikator } \\
\hline 1 & Waktu siklus & Waktu penyelesaian suatu proses kerja dengan satuan waktu \\
2 & Waktu setup & waktu pengatur ulang / persiapan mesin sebelum proses \\
3 & Jumlah hari dan jam kerja & Jumlah hari dan jam kerja aktif \\
4 & Jumlah mesin produksi & Jumlah mesin yang ada pada masing-masing work center \\
5 & Kebutuhan kapasitas & Jumlah waktu sumber daya untuk memenuhi permintaan \\
6 & Ketersediaan kapasitas & konsumen \\
\hline
\end{tabular}


Muhamad Abdul Jumali dan Yitno Utomo: Perencanaan Kebutuhan Kapasitas Waktu Produksi Produk Spon Alas Tidur (Studi Kasus: Perusahaan Alas Tempat Tidur di Sidoarjo)

3. HASIL DAN PEMBAHASAN

a. Alur Proses Produksi Spon Alas Tempat Tidur

Alur proses produksi spon alas tempat tidur adalah sebagai berikut:

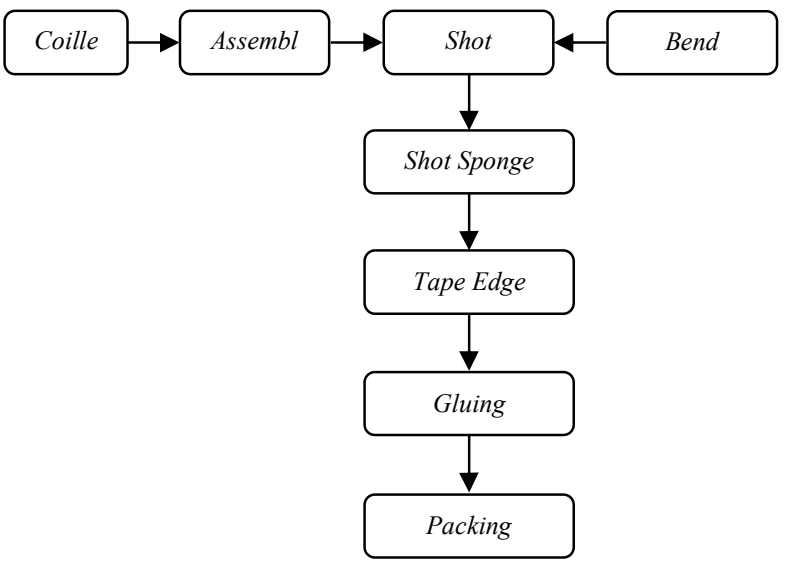

\section{Gambar 1 Alur Proses Produksi Spon Alas Tempat Tidur}

Dari gambar alur produksi spon alas tempat tidur dapat diketahui adalah pertama coiller work station, adalah proses pembuatan bonnel peer berbentuk spiral yang berasal dari bahan baku utama yakni kawat tahan tekuk. Setelah bonnel peer siap, bonnel peer di rangkai untuk dijadikan rangka kasur dan disebut proses assembler work station. Bend frame work station atau tekuk frame adalah proses pembuatan bingkai frame yang berasal dari kawat. Hasil dari assembler work station dan bend frame work station di rangkai menjadi rangka dalam spon alas tempat tidur, proses ini disebut dengan shot frame work station. Proses selanjutnya adalah penyusunan bagian dalam (hasil shot frame work station), spon atas dan spon bawah bawah (rangka, busa layer dan kain spon alas tempat tidur), proses ini disebut shot sponge bed work station. Setelah rangkain spon alas tempat tidur sudah tertata dengan rapi, maka proses selanjutnya adalah proses penjahitan melingkar seluruh bagian pinggir bed, pemasangan beberapa accessories lubang angin dan pelabelan sesuai spesifikasi, proses ini disebut dengan tape edge work station. Untuk membuat sponge bed jauh berkualitas maka proses selanjutnya adalah penyusunan busa layer diatas spon yang sudah di jahit kain pinggiran dan kemudian dijahit kembali dengan kain bagian atasnya, proses ini disebut gluing work station. Dan proses akhir adalah packing, yaitu pengemasan sponge bed yang sudah dijahit tape edge menggunakan plastik / mika sesuai dengan spesifikasi.

\section{b. Perbandingan kapasitas tersedia dengan Rough Cut Capaciy Planning (RCCP)}

Metode yang digunakan dalam menganalisa dan mengelolah data hasil studi kasus ini yakni metode RCCP. Perbandingan data kapasitas waktu produksi yang tersedia dengan yang dibutuhkan di setiap work center selama periode akhir triwulan 2018 pada assembler, shot frame, shot sponge bed, tape edge dan packing memiliki kapasitas yang mampu memenuhi kebutuhan kapasitas selama periode akhir triwulan 2018. Tetapi berbeda dengan bagian coiller dan bend frame yang pada beberapa periode triwulan tidak mampu mencukupi kebutuhan kapasitas yang sudah dihitung secara berturut-turut sebesar 19\%, 0,44\% dan 29\%. Sedangkan pada bend frame yang juga mengalami kekurangan kapasitas pada secara berturut-turut sebesar 20\%, 2\%, 30\%. Oleh karena itu, perencanaan ulang kapasitas produksi perlu dilakukan 
Muhamad Abdul Jumali dan Yitno Utomo: Perencanaan Kebutuhan Kapasitas Waktu Produksi Produk Spon Alas Tidur (Studi Kasus: Perusahaan Alas Tempat Tidur di Sidoarjo)

pada coiller dan bend frame dengan cara penyesuaian beban kerja (readjusment).

Kapasitas tersedia atau Available capacity dapat dihitung dengan menggunakan persamaan sebagai berikut :

\section{Available capacity}

$=\sum \frac{\text { Workdays }}{\text { Mounth }} \times \sum \frac{\text { Man hour }}{\text { Day }} \times \sum \frac{\text { Machine }}{\text { Unit }}$

Sedangkan untuk kapasitas dibutuhkan atau Needed capacity
dapat
dihitung
dengan
menggunakan persamaan:

Needed capacity $=$ Setup $+\left(\right.$ Demand $\left.X \frac{\text { Time }}{\text { Unit }}\right)$

c. Master Planning Schedulle

Berikut ini merupakan tabel 2 yang menggambarkan perbandingan kapasitas yang dibutuhkan dan yang tersedia yang dihitung berdasarkan jumlah hari kerja yang berjalan di perusahaan selama periode tahun.

Tabel 2 Master Planning Schedulling

\begin{tabular}{lccccc}
\hline \multicolumn{1}{c}{ Proses } & $\begin{array}{c}\text { Kapasitas } \\
\text { dibutuhkan }\end{array}$ & $\sum$ mesin & $\begin{array}{c}\text { N hari kerja } \\
\text { dibutuhkan }\end{array}$ & $\begin{array}{c}\sum \text { hari } \\
\text { kerja } \\
\text { tersedia }\end{array}$ & $\begin{array}{c}\sum \text { hari } \\
\text { kerja } \\
\text { lebih }\end{array}$ \\
\hline Coiller & 3250 & 2 & 232 & 297 & 65 \\
Assembler & 3282 & 3 & 156 & 297 & 141 \\
Bend frame & 1644 & 1 & 235 & 297 & 62 \\
Shot frame & 3282 & 3 & 156 & 297 & 141 \\
Shot sponge & 3282 & 3 & 156 & 297 & 141 \\
Gluing & 689 & 1 & 98 & 297 & 199 \\
Tape edge & 2873 & 3 & 137 & 297 & 160 \\
Packing & 1371 & 2 & 98 & 297 & 199 \\
\hline
\end{tabular}

Berdasarkan tabel 2 di atas, dalam bahwa semua work center mengalami kelebihan kapasitas untuk memenuhi permintaan pasar. Dampak yang akan ditimbulkanbanyak sumber daya atau resource yang terbuang sehingga banyak kerugian bagi perusahaan. Maka, yang bisa dilakukan oleh perusahaan yakni re-schedulling. Hal ini dilakukan untuk menyeimbangkan antara kebutuhan kapasitas waktu tersedia sesuai dengan kapasitas dibutuhkan. Solusi alternatif pertama adalah operator produksi yang biasanya bekerja 6 hari dalam seminggu bisa jadi re-schedulling menjadi 5 hari kerja seminggu sehingga kapasitas yang dihasilkan lebih seimbang sesuai kebutuhan. Solusi alternatif kedua adalah perubahan strategi pemasaran atau merefleksikan kapasitas perusahaan terhadap demand.

\section{KESIMPULAN}

Berdasarkan hasil analisa dan pembahasan menunjukkan bahwa perbandingan total kapasitas kebutuhan waktu produksi tersedia terhadap kapasitas kebutuhan waktu dibutuhkan selama periode tahunan kedepan pada setiap workstation yang dimiliki perusahaan yakni rata-rata kelebihan kapasitas kelebihan waktu produksi sebesar $45 \%$ dikarenakan kapasitaskebutuhan waktu produksi yang dimiliki tidak merata, sehingga dampak nyata yang ditimbulkan permintaan konsumen tidak bisa dipenuhi. Maka diperlukan penyesuaian (re-adjusment) beban kerja dan penjadwalan ulang (reschedulling) agar seluruh kebutuhan kapasitas bisa terpenuhi sehingga distribution service terhadap demand bisa di kendalikan. dengan discount system. Solusi alternatif ketiga adalah 
Muhamad Abdul Jumali dan Yitno Utomo: Perencanaan Kebutuhan Kapasitas Waktu Produksi Produk Spon Alas Tidur (Studi Kasus: Perusahaan Alas Tempat Tidur di Sidoarjo)

\begin{tabular}{cl}
\hline 5. UCAPAN TERIMA KASIH & Teknik Industri dan Incubator Industrial \\
Ucapan terima kasih penulis & Merchendise yang telah membantu \\
sampaikan kepada Asisten Laboratorium & menganalisiskan data-data penelitian.
\end{tabular}

\section{DAFTAR PUSTAKA}

Ayu Christanty, Ellysa Maria. Optimasi Kapasitas Produksi Dalam Penyusunan Jadwal IndukProduksi Menggunakan Integer Linear Programming (ILP). Jurnal Rekayasa dan Manajemen Sistem Industri Vol.2 No.6 Teknik Industri Universitas Brawijaya.

Nasution, Arman Hakim. 1999. Perencanaan dan Pengendalian Produksi.Surabaya: GunaWidya.

Paksi R, Shoyuke. Perencanaan Produksi Sari Apel Dengan Metode Transportasi DiKSUBrosemBatu Malang.Jurnal Jurusan Teknologi Pertanian FTP-Unibraw.

Rumiris, Ira Hutagalung. Perencanaan Kebutuhan Kapasitas Produksi PT XYZ. JurnalTeknikIndustri FT USU Vol.2, No.1, Mei 2013.

Santoso, Budi. Perencanaan Kapasitas Waktu Produksi Dengan Menggunakan Metode RoughCutCapacity Planning (RCCP) Pada Produk "Bale Cover" (Studi Kasus Di PT. Wihartakarya Agung Gresik). Prosiding Seminar Nasional Aplikasi Sains \& Teknologi (SNAST) Periode III Yogyakarta, 3 November 2012

Sanita. 2010. Implementasi Master Production Schedule (MPS) Dan Rough- Cut CapacityPlanning (RCCP) Untuk Disruptive Demand (Studi Kasus Di PT Sinar terang Logamjaya).Bandung : Universitas Widyatama

Sirait,Marta Elissa. Perencanaan Kebutuhan Kapasitas (Rough Cut Capacity Planning) Industri Pengolahan Peralatan Rumah Tangga Di PT. X. E-jurnal Teknik Industri FT USU Vol.2, No.2 Juni 2013 pp.28-34

Zulianto, Agus. Analisi Kapasitas Mesin Menggunakan Metode Rough Cut Capacity Planning (RCCP) untuk mengantisipasi Perkembangan Permintaan Sepatu Studi Kasus PT. Prima Dinamika Sentosa.Jurnal Pendidikan Teknik Mesin Vol.01, No.01, (2012) 